\title{
Pure Relationship - Open Heart. Leadership community in an Icelandic school in times of Globalization
}

\author{
Inga Sigrún Atladóttir \\ The Leadership Community
}

\begin{abstract}
The period spanning the last decades has been called the time of globalization. It is evidenced by comparative studies that Iceland is one of the most globalized nations in the world. Studies have also shown that the Icelandic school system has not managed to adapt fully to these changes.

My research (2012) suggests that Icelandic principals lack leadership skills and methods for dealing with communication problems and inducing employees and students to tackle difficult tasks. My aims were to changing the school culture and the leadership skills of the individual to improve the wellbeing of the students and staff, especially in dealing with antisocial behaviors and bullying.

Data was collected with quantitative research methods and subsequently I implemented a school policy called the Leadership Community in a small school in Iceland. This school policy is still at work in the school.

Educational institutions in the time of globalization bear characteristics of an open social system and personal communication. The concepts that I used as a foundation to change the school culture are "pure relationship" and "open heart". These theories are based on diversity, honesty and trust and they show how the characteristics of globalization can be used as a basis for these values.

In my lecture I will explain the theory and practice behind the school policy, the results of my research, what changes I have made in the school during the last seven years and how they have affected the wellbeing of students and staff in the school.
\end{abstract}

Keywords: Leadership, bullying, community, violence, school-culture. 